УДК 342.5

DOI: 10.33184/pravgos-2020.3.7

\title{
К ВОПРОСУ О ПРАВОВОЙ ПРИРОДЕ КОЛЛИЗИОННОГО ПРАВА
}

\section{ЛАТЫПОВА Наталия Сергеевна}

кандидат юридических наук, дочент кафедры теории государства и права Института права ФГБОУ ВО «Башкирский государственный универcumem», г. Уфа, Россия. E-mail: marchrose@yandex.ru

\section{ЯМАЛЕТДИНОВА Наталья Владимировна}

кандидат юридических наук, доцент кафедры теории государства и права Института права ФГБОУ ВО «Башкирский государственный универcumem», г. Уфа, Россия. E-mail: fnv80-80@mail.ru

Термин «коллизионное право» прочно вошел в категориальный аппарат российской юридической науки, однако до настоящего времени не сложилось единого подхода к определению его места в системе права. В статье анализируется научная дискуссия, освещаются основные точки зрения в сфере исследования коллизионного права. Цель: анализ правовой природы коллизионного права и определение основных тенденций его развития. Методы: эмпирические методы сравнения, описания, интерпретации; теоретические методы формальной и диалектической логики. Применялись частнонаучные методы: юридико-догматический и метод толкования правовых норм. Результаты: юридическая природа коллизионного права проявляется, прежде всего, в коллизионных нормах, рассредоточенных в различных отраслях права, обеспечивающих системность и структурную организованность права. Следовательно, оно не имеет ярко выраженной отраслевой принадлежности. Авторы предлагают рассматривать коллизионное право как комплексный межотраслевой правовой институт.

Ключевые слова: коллизии норм права; юридическая коллизия; противоречия в праве; коллизионное право; федеральное коллизионное право.

Современное российское законодательство характеризуется высокими темпами развития и представляет собой сложную многоуровневую совокупность правовых предписаний, объективно отягощенных противоречивостью, несогласованностью и разночтением. Сложность правотворческого процесса порождает диссонанс между предписаниями нормативных правовых актов. Юридические коллизии мешают согласованному развитию всех элементов правовой системы, что, в свою очередь, негативно сказывается на эффективности механизма правового регулирования, обеспечении законности и правопорядка, свободной реализации прав и законных интересов граждан. Система права, сколь совершенной бы она ни была, не может предотвратить возникновение противоречий меж- 
ду нормами национального и международного, федерального и регионального законодательства, предписаниями различных отраслей права.

В отечественной юридической науке не сложилось единого подхода к пониманию отраслевой правовой природы коллизионного права. Длительное время коллизионные нормы рассматривались исключительно в сфере регламентации международных отношений или правовых отношений, осложненных иностранным элементом, сквозь призму предписаний международного частного права. Однако в последние годы в юриспруденции отчетливо прослеживается тенденция на укрупнение предмета коллизионного права и рассмотрение его не только с точки зрения гармонизации и унификации международного законодательства, но и применительно к национальному праву.

Особенно актуальным подобное «широкое» понимание коллизионного права видится в отношении стран с федеративной формой государственного устройства в связи с наличием в них двухуровневой системы законодательства: федеральной и региональной. Конституцией Российской Федерации в официальный юридический лексикон прочно внедрен термин «федеральное коллизионное право» (ст. 71). Соглашаясь с мнением С.И. Носова, отметим, что Конституция РФ в значительной мере расширила сферу применения норм коллизионного права, установив нормы-запреты (запрет присвоения государственной власти - ч. 4 ст. 3), нормы-приоритеты (определение приоритета общепризнанных принципов и норм международного права и международных договоров Российской Федерации - ч. 4 ст. 15), процедурные нормы (использование согласительных процедур для разрешения разногласий между органами государственной власти Российской Федерации и органами государственной власти субъектов Российской Федерации, а также между органами государственной власти субъектов Российской Федерации - ч. 1 ст. 85) [4, с. 73]. Однако, несмотря на конституционное закрепление новой для российского права дефиниции, в юридической доктрине не сложилось единообразного подхода к пониманию коллизионного права в целом и к федеральному коллизионному праву в частности [11, с. 20].

Наиболее детально проблемы коллизионного права исследованы в трудах А.Ю. Тихомирова, включившего в его содержание принципы предотвращения коллизий, процедуры преодоления споров, законные интересы и притязания, юридическую ответственность участников коллизионных отношений, правовые идеи и концепции. Исследуя местоположение коллизионного права в системе российского права, А.Ю Тихомиров определил его как комплексную суперотрасль, к предмету которой относятся общественные отношения, урегулирование которых вызывает разногласия и споры. Федеральное коллизионное право, по мнению ученого, следует считать подотраслью конституционного права [9, с. 339]. 
Наличие формулировки «федеральное коллизионное право» предусмотрено в конституционных системах Германии, Австрии, Швейцарии и «является юридическим ориентиром и стимулом для формирования подобной отрасли» [10, с. 367]. Конституции зарубежных стран в качестве средств и способов предотвращения и разрешения коллизий определяют: 1) нормативное закрепление основных механизмов предотвращения коллизий: предварительный конституционный контроль, верховенство и незыблемость конституционных принципов, участие органов конституционного контроля в законотворческом процессе; 2) участие парламента в формировании органов конституционного контроля в целях поддержания авторитетности их деятельности и нивелирования коррупциогенных влияний; 3) расширение полномочий органов конституционного контроля по разрешению коллизий [7, с. 71].

Подобных взглядов на определение федерального коллизионного права в системе российского права придерживается и И.А. Стародубцева. Несмотря на частичное совпадение предмета, структуры и принципов конституционного и федерального коллизионного права, Инна Алексеевна конкретизирует предмет последнего, включая в него «общественные отношения, связанные с предотвращением и разрешением всех коллизий, конфликтов, противоречий и споров в государстве, регулируемые нормами конституционного права на федеральном уровне» [8, с. 60]. Следует отметить, что И.А. Стародубцева придерживается отличного от А.Ю. Тихомирова мнения в вопросе определения коллизионного права, которое представляется как перспективная и на данный момент времени неоформившаяся комплексная отрасль права, теоретическое и нормативное развитие которой детерминировано необходимостью минимизации негативного воздействия юридических коллизий на правовую систему [8, с. 76].

Можно констатировать, что в отечественной правовой науке не оформился монистический подход к отраслевой природе коллизионного права. Так, Н.А. Власенко скептически относится к возможности определения коллизионного права как в качестве суперотрасли права, так и в качестве самостоятельной отрасли. Коллизионный механизм не имеет отраслевой окраски, а коллизионные нормы «могут иметь "прописку" в различных отраслях» [1, с. 15]. Следовательно, коллизионное право рассматривается им как универсальный инструмент российского права, обеспечивающий структурность права и системность его действия. Коллизионное право - средство поддержания единого правового порядка в государстве, гарант законности в обществе. Федеральное коллизионное право, по мнению профессора, несмотря на законодательное его закрепление в нормах Конституции Российской Федерации, не следует относить к подотрасли конституционного права. Идея коллизионного права, и в том числе федерального коллизионного права, актуальна и востребована с 
точки зрения систематизации коллизионных принципов при условии разработки федерального коллизионного закона. Однако с 1993 г. практических шагов по реализации данных идей, заложенных в Основном законе России, к сожалению, не предпринято.

Исследование вопроса отраслевой принадлежности коллизионного права стало также предметом размышлений Д.С. Милинчук. В диссертационном исследовании на тему «Коллизионное право как межотраслевой институт российского права» последовательно изложена концепция понимания коллизионного права как межотраслевого юридического явления, возникающего на стыке неоднородных отраслей права. Наличие коллизий во всех отраслях права (гражданском, трудовом, налоговом, административном и т. д.) позволило автору сделать закономерный вывод о межотраслевом характере данного правового института. В различных отраслях права разработаны способы разрешения юридических противоречий: так, в международном частном праве подобные конфликты разрешаются путем выбора соответствующей формулы прикрепления, в конституционном праве разрешение конфликтов норм происходит в соответствии с федеральным коллизионным правом (п. «П», ст. 71 Конституции РФ) [5, с. 197]. Следовательно, коллизионным правом регламентируется однородный круг отношений, который образует межотраслевой институт права.

Динамизм развития общественных отношений и, как следствие, появление разнообразных правовых коллизий и способов их разрешения и предопределили высокий интерес ученых-правоведов к исследованию коллизионного права. Определение коллизионного права в качестве самостоятельной отрасли права либо суперотрасли предполагает наличие классических критериев деления права на отрасли: предмета и метода правового регулирования. Предметом правового регулирования является качественно однородный тип общественных отношений (в семейном праве - брачно-семейные отношения, в гражданском праве - имущественные и связанные с ними личные неимущественные отношения, в административном праве - общественные отношения, возникающие в связи и по поводу практической реализации исполнительной власти). В коллизионном праве крайне затруднительно выявить какой-либо самостоятельный круг общественных отношений, оно регламентирует порядок разрешения правовых конфликтных ситуаций во всех сферах общественной жизни. В данном случае уместно говорить о том, что коллизионное право представляет собой совокупность норм, посредством которых разрешаются коллизионные ситуации, норм, обеспечивающих структурность и системность права.

Вторым критерием определения автономности отрасли права является наличие специфического метода правового регулирования, под которым понимается совокупность различных способов и приемов правового 
воздействия на общественные отношения, составляющие предмет отрасли. Метод правового регулирования структурно представлен следующими компонентами: порядок возникновения субъективных прав и обязанностей, степень самостоятельности субъектов правоотношения, а также способы регулирования и обеспечения поведения субъектов права. Усовершенствование законодательства, толкование и гармонизация права, принятие модельных законов, рассматриваемые как основные формы коллизионного регулирования, не представляют собой единого метода правовой регламентации и заимствованы из других отраслей права.

Таким образом, можно сформулировать вывод о том, что коллизионное право, не обладая уникальными предметом и методом правового регулирования, не отвечает традиционным критериям деления права на отрасли. Наиболее перспективным подходом к определению правовой природы коллизионного право представляется понимание его как комплексного межотраслевого правового института, поскольку наличие коллизий характерно для всех отраслей права, а «круг регулируемых коллизионным правом отношений направлен на упорядочение правоотношений, возникающих в результате выбора между конфликтующими нормами права» [6, с. 11]. Следовательно, коллизионное право - это межотраслевой правовой институт, консолидирующий правовые нормы, регулирующие правоотношения, связанные с воздействием на юридические коллизии, с целью достижения согласованности и непротиворечивости правового регулирования.

Наличие коллизионных норм характеризует право как высокоорганизованную систему. Система коллизионного права отличается сложностью и многообразием. Представляется целесообразным выделить в ней как минимум две группы норм, регулирующих правовые конфликты и противоречия: между национальным и международным правом, а также в рамках национальной правовой системы. Профессор С.И. Носов справедливо отмечает, что в современной «юридической литературе коллизионное право все чаще рассматривается в широком понимании, выходящим за рамки традиционного представления, в виде норм международного частного права» $[4$, с. 81$]$.

Особенности норм коллизионного права, регламентирующих сферу внутреннего национального права, отображают проблемы и противоречия на всех этапах развития современного российского государства. Конституция Российской Федерации нормативно закрепила законотворческие полномочия субъектов России в сфере регламентации вопросов совместного и исключительного ведения субъектов [2, с. 169]. Активное использование регионами данной компетенции привело к стремительному росту массива нормативных правовых актов, содержащих не только 
незначительные юридические ошибки, но и серьезные противоречия, имеющие принципиальный характер.

На начальном этапе становления Российской Федерации и оформления конституционной модели разграничения полномочий с 1993 г. по 1999 г. субъекты практически самостоятельно определяли пределы своей правотворческой деятельности и нередко вмешивались в компетенцию Федерации, что воплощалось в региональном законодательстве. Так, в 1993 г. на протяжении 4 месяцев в России фактически существовал субъект, не предусмотренный Федеративным договором 1992 г. - Уральская республика, преобразованная из Свердловской области с целью повышения ее статуса в составе Российской Федерации и обретения значительной экономической и законодательной самостоятельности. Конституция Республики Алтай содержала положения о ее суверенности, принадлежности субъекту права собственности на природные ресурсы, находящиеся на ее территории, и т. п. В 1994 г. между Республикой Башкортостан и Республикой Чувашия был заключен Договор о дружбе и сотрудничестве, основанный на признании государственного суверенитета обеих сторон ${ }^{1}$. Таким образом, законодательство «молодой» Российской Федерации нередко отличалось противоречивостью и непоследовательностью, что, в свою очередь, понижало эффективность правового регулирования в целом. Переходное состояние системы государственной власти, незрелость политической системы и незначительный опыт применения норм коллизионного права для разрешения внутригосударственных юридических конфликтов и противоречий привели к несогласованности норм российского законодательства.

Значительная работа по укрупнению и централизации государственной власти, проведенная в период с 2000 г. по 2005 г., затронувшая в том числе и законодательную сферу, привела к существенному сокращению конфликтующих и взаимоисключающих норм в национальном праве. Так, Конституционным Судом РФ в 2000 г. отдельные нормы Конституции Республики Алтай и связанные с ними нормативные правовые акты, воспроизводящие или содержащие эти положения, были признаны несоответствующими Основному закону Российской Федерации и подлежащими отмене ${ }^{2}$.

\footnotetext{
${ }^{1}$ Официальный портал органов власти Чувашской республики [Электронный ресурс]. URL: http://www.cap.ru (дата обращения: 10.05.2020).

${ }^{2}$ Постановление Конституционного Суда РФ от 07.06.2000 № 10-П «По делу о проверке конституционности отдельных положений Конституции Республики Алтай и Федерального закона "Об общих принципах организации законодательных (представительных) и исполнительных органов государственной власти субъектов Российской Федерации"» [Электронный ресурс]. URL: https://legalacts.ru/doc/postanovlenie-konstitutsionnogo-sudarf-ot-07062000-n/ (дата обращения: 10.05.2020).
} 
Особую актуальность и остроту проблема коллизий приобретает в публичном праве, поскольку затрагивает законные интересы и потребности не только частных лиц, но и государства и общества. В системе права Российской Федерации можно выделить следующие виды коллизий в сфере норм публичного права: коллизии между предписаниями федеральных нормативных правовых актов, коллизии между федеральными нормативными правовыми актами и нормативными правовыми актами субъектов Российской Федерации и коллизии между нормативными актами субъектов Российской Федерации [3, с. 57]. Полагаем, что в ближайшем будущем количество правовых коллизий, несомненно, будет возрастать, следовательно, пропорционально этому в научном мире будет востребована тема исследования коллизионного права.

Изложенное позволяет сформулировать выводы относительно тенденций развития коллизионного права в России. Правовые коллизии оказывают негативное влияние на российскую правовую систему, поскольку эффективность ее функционирования напрямую опосредована согласованностью и взаимозависимостью законодательной базы. Коллизионное право на данный момент находится на стадии активного становления. В современной юридической литературе до сих пор не сложилось единообразного подхода к определению отраслевой принадлежности коллизионного права. Его правовая природа раскрывается, прежде всего, через сами коллизионные нормы, рассредоточенные в различных отраслях права. В связи с чем наиболее перспективным подходом к определению институциональной принадлежности коллизионного права представляется понимание его как комплексного межотраслевого правового института.

\section{Библиографические ссылки}

1. Власенко Н.А. Коллизионное право России: состояние и перспективы // Журнал российского права. 2017. № 6. С. 5-18.

2. Ибрагимова Ф.М., Тулупова Е.О. Актуальные проблемы конституционного развития в сфере разграничения предметов ведения и полномочий между федерацией и ее субъектами // Правовое государство: теория и практика. 2014. № 2 (36). С. 168-171.

3. Латыпова Н.С. Развитие внешних форм сотрудничества органов местного самоуправления // Правовое государство: теория и практика. 2019. № 4 (58). С. 54-58.

4. Носов С.И. Коллизионное право: проблемы институализации // Социология власти. 2012. № 2. С.72-82. 
5. Милинчук Д.С. Коллизионное право как межотраслевой институт системы российского права // Вестник КГУ им. Н.А. Некрасова. 2016. № 1. С. 196-198.

6. Милинчук Д.С. Коллизионное право как межотраслевой институт российского права : резюме дис. ... канд. юрид. наук. М. : НИУ ВШЭ, 2018.

7. Стародубцева И.А. Коллизионные отношения как разновидность конституционно-правовых : монография. Воронеж : Издательский дом ВГУ, 2016.

8. Стародубцева И.А. Конституционные принципы федерального коллизионного права // Журнал российского права. 2012. № 6. С. 59-65.

9. Тихомиров А.Ю. Правовое регулирование: теория и практика. М. : Формула права, 2008.

10. Тихомиров А.Ю. Коллизионное право и отклонения в правовой сфеpe // Право и политика. 2013. № 3 (159). С. 363-370.

11. Ямалетдинова Н.В. Правовое регулирование создания и функционирования согласительных комиссий в Федеральном Собрании Российской Федерации // Вестник Института права Башкирского государственного университета. 2019. № 2 (4). С. 19-25.

Дата поступления 25.06.2020

DOI: $10.33184 /$ pravgos-2020.3.7

\section{ON THE LEGAL NATURE OF LAW OF CONFLICT}

\section{LATYPOVA Natalia Sergeevna}

Candidate of Sciences (Law), Assistant Professor of the Chair of Theory of State and Law, Institute of Law, Bashkir State University, Ufa, Russia.

E-mail: marchrose@yandex.ru

\section{YAMALETDINOVA Natalia Vladimirovna}

Candidate of Sciences (Law), Assistant Professor of the Chair of Theory of State and Law, Institute of Law, Bashkir State University, Ufa, Russia.

E-mail: fnv80-80@mail.ru

The term "law of conflict" has firmly entered the categorical apparatus of Russian legal science, but today there is no unified approach to determining its place in the legal system. The article analyzes the scientific discussion, highlights the main points of view in the field of researching law of conflict. Purpose: to analyze the legal nature of law of conflict and determine the main trends in its development. Methods: empirical methods of comparison, description, interpretation; theoretical methods of formal and dialectical logic. Specific scientific methods are used: legal-dogmatic and method of interpretation of legal norms. Results: the legal nature of law of conflict is manifested primarily in conflict of laws dispersed in various branches of law that ensure law consistency and structural organization. Therefore, it does not belong expressly to 
any branch. The authors propose to consider law of conflict as a complex inter branch-legal institution.

Key words: conflicts of law, legal conflict, contradictions in law, law of conflict, Federal law of conflict.

\section{References}

1. Vlasenko N.A. Kollizionnoye pravo Rossii: sostoyaniye i perspektivy (Law of Conflict in Russia: state and prospects), Zhurnal rossiyskogo prava, 2017, No. 6, pp. 5-18. 2. Ibragimova F.M., Tulupova Ye.O. Aktual'nyye problemy konstitutsionnogo razvitiya v sfere razgranicheniya predmetov vedeniya i polnomochiy mezhdu federatsiyey i yeye sub"yektami (Actual problems of constitutional development in the sphere of delimiting the subjects of jurisdiction and powers between the federation and its subjects), Pravovoye qosudarstvo: teoriya i praktika, 2014, No. 2 (36), pp. 168-171.

3. Latypova N.S. Razvitiye vneshnikh form sotrudnichestva organov mestnogo samoupravleniya (Development of external forms of cooperation between local government bodies), Pravovoye gosudarstvo: teoriya i praktika, 2019, No. 4 (58), pp. 54-58.

4. Nosov S.I. Kollizionnoye pravo: problemy institualizatsii (Law of Conflict: problems of institutionalization), Sotsiologiya vlasti, 2012, No. 2, pp. 72-82.

5. Milinchuk D.S. Kollizionnoye pravo kak mezhotraslevoy institut sistemy rossiyskogo prava (Law of Conflict as an interdisciplinary institution of the Russian law system), Vestnik KGU im. N.A. Nekrasova, 2016, No. 1, pp. 196-198.

6. Milinchuk D.S. Kollizionnoye pravo kak mezhotraslevoy institut rossiyskogo prava (Law of Conflict as an interdisciplinary institution of Russian law), rezyume dis. ...kand. yurid. nauk, Moscow, NIU VSHE, 2018.

7. Starodubtseva I.A. Kollizionnyye otnosheniya kak raznovidnost' konstitutsionno-pravovykh (Collisional relations as a kind of constitutional and legal relations), monografiya, Voronezh, Izdatel'skiy dom VGU, 2016.

8. Starodubtseva I.A. Konstitutsionnyye printsipy federal'nogo kollizionnogo prava (Constitutional principles of federal law of conflict), Zhurnal rossiyskogo prava, 2012, No. 6, pp. 59-65.

9. Tikhomirov A.Yu. Pravovoye regulirovaniye: teoriya i praktika (Legal regulation: theory and practice), Moscow, Formula prava, 2008.

10. Tikhomirov A.Yu. Kollizionnoye pravo i otkloneniya v pravovoy sfere (Conflict law and deviations in the legal sphere), Pravo $i$ politika, 2013, No. 3 (159), pp. 363-370.

11. Yamaletdinova N.V. Pravovoye regulirovaniye sozdaniya i funktsionirovaniya soglasitel'nykh komissiy v Federal'nom sobranii Rossiyskoy Federatsii (Legal regulation of the creation and functioning of conciliation commissions in the Federal Assembly of the Russian Federation), Vestnik Instituta prava Bashkirskogo gosudarstvennogo universiteta, 2019, No. 2 (4), pp. 19-25.

Received: 25.06.2020 